\title{
Turismo esportivo de experiência em museus e tours em estádios de futebol
}

\author{
Sports tourism experience in museums and tours in football stadiums \\ Turismo deportivo de experiencia en museos y tours en estadios de fútbol
}

Marcio Ferreira Bezerra

Universidade do Grande Rio (UNIGRANRIO), Brasil

marcio_ferreira86@yahoo.com.br

DOI: https://doi.org/10.18472/cvt.19n3.2019.1516

Redalyc: http://www.redalyc.org/articulo.oa?

Pedro Henrique Curvello

Universidade do Grande Rio (UNIGRANRIO), Brasil

phdcurvello@yahoo.com.br

Deborah Moraes Zouain

Universidade do Grande Rio (UNIGRANRIO), Brasil

deborahzouain@gmail.com

id $=115461709006$

Recepción: 08 Noviembre 2017

Aprobación: 04 Julio 2019

\section{Resumo:}

O futebol é singular quanto ao poder de atração, mobilização de pessoas e transmissão de emoções e sentimentos. Para instituições que internacionalizam suas marcas, seu público alvo passa a não ser mais somente o local e com isso, abre uma nova oportunidade de receita através do turismo esportivo, com visitação a museus e tour nos estádios. Nesse contexto, o objetivo desse estudo é investigar se os espaços esportivos de Boca Juniors, Real Madrid, Barcelona, Benfica e Maracanã estão alinhados com a teoria sobre turismo de experiência como forma de qualificação de um atrativo turístico. Assim, foi realizada uma pesquisa qualitativa e exploratória, com coleta de dados realizada in loco, utilizando a técnica de observação não participativa. A análise foi feita englobando aspectos multidimensionais relacionados à experiência. Os resultados apontam que tais locais são mais do que espaços reservados à memória, pois oferecem uma experiência que leva emoção por novas perspectivas, através do uso de tecnologias.

Palavras-chave: Turismo de experiência, futebol, museus.

\section{Abstract:}

Football is unique as to the power of attraction, mobilization of people and transmission of emotions and feelings. For institutions that internationalize their brands, their target audience is no longer just the place and with that, it opens a new revenue opportunity through sports tourism, with visits to museums and touring the stadiums. In this context, the objective of this study is to investigate whether the sporting spaces of Boca Juniors, Real Madrid, Barcelona, Benfica and Maracanã are aligned with the theory about tourism of experience as a form of qualification of a tourist attraction. Thus, a qualitative and exploratory research was performed, with data collection performed in loco, using the technique of non-participatory observation. The analysis was made encompassing multidimensional aspects related to the experience. The results point out that such places are more than spaces reserved for memory, because they offer an experience that brings excitement to new perspectives, through the use of technologies.

KEYWORDS: Tourism experience, footbal, museums.

\section{Resumen:}

El fútbol es singular en cuanto al poder de atracción, movilización de personas y transmisión de emociones. Para las instituciones que internacionalizan sus marcas, su público objetivo pasa a no ser sólo el local y con ello, abre una nueva oportunidad de ingresos a través del turismo deportivo, con visitas a museos y tour en los estadios. En este contexto, el objetivo de este estudio es investigar si los espacios deportivos de Boca Juniors, Real Madrid, Barcelona, Benfica y Maracaná están alineados con la teoría sobre turismo de experiencia como forma de calificación de un atractivo turístico. Así, se realizó una investigación cualitativa y exploratoria, con recolección de datos realizada in loco, utilizando la técnica de observación no participativa. El análisis se hizo englobando aspectos multidimensionales relacionados con la experiencia. Los resultados apuntan que tales locales son más que espacios reservados a la memoria, pues ofrecen una experiencia que lleva emoción por nuevas perspectivas, a través del uso de tecnologías.

Palabras clave: Turismo de experiencia, fútbol, museos. 


\section{INTRODUÇÃO}

"O futebol como esporte e como um negócio, numa visão mais ampla, é único quanto à dimensão de seu poder de atração, ao tamanho do público e à habilidade de despertar emoções” (CARSON, 2015, p. 224). Assim, atualmente o futebol não é mais visto somente como um esporte, mas como um negócio complexo que movimenta bilhões de dólares por ano ao redor do mundo.

Marques (2007) fala em mercantilização do esporte e uma cultura esportiva do consumo, mencionando dentre uma das formas de difusão desse comércio, o mercado de produtos e serviços esportivos. Assim criouse o que se chama de espetacularização do esporte, onde se exigiu muito mais profissionalismo e estrutura por parte dos clubes envolvidos, principalmente os grandes clubes que movimentam a paixão de torcedores. "Com a chegada do século XXI, para enfrentar as necessidades econômicas crescentes, os clubes, em especial os maiores, foram gerando uma fonte de renda alternativa: o marketing” (SORIANO, 2010, p. 22). O marketing esportivo se apresentou como uma forma muito importante na comunicação com os torcedores e na promoção de produtos e serviços oferecidos pelos clubes. Com isso, houve uma melhora na percepção de novas oportunidades e benefícios que podiam ser gerados através do estudo de seu mercado consumidor, que é apaixonado e fiel a sua marca.

Segundo Melo Neto (2013), há algumas definições que se enquadram no marketing esportivo, dentre elas: o uso da força da paixão como elemento ativador dos processos de comunicação e de vendas; a promoção de vivências proporcionadas pelo consumo do esporte como produto; a busca de espetacularização do consumo esportivo; a entrega de valores, atributos e benefícios de alto teor emocional; a construção e propagação de sonhos que visam reforçar as conexões do torcedor.

Assim, clubes investem em produtos licenciados, patrocínios, comunicação em redes sociais, museus esportivos interativos, visitação em estádios e, até mesmo, criação de televisão e rádio próprios. Todas as formas de gerar receita, além do campo de jogo. Isso porque o consumidor do futebol se destaca por se diferenciar dos demais por conta de sua paixão e de sua fidelidade, o que faz com que as ações de marketing focassem, principalmente, na exploração de sua emoção como gatilho de identificação e compra.

A utilização dos espaços nos estádios/arenas para tours e museus, são atividades que têm gerado grandes receitas, principalmente, para aqueles que apresentam tais serviços pautados em novas experiências para os torcedores. Clubes de marca internacionalizada, trabalham o marketing desses serviços e já se tornaram atrativos turísticos de suas cidades, onde recebem milhares de torcedores/turistas por mês em suas instalações, em busca da vivência na história dos clubes e suas conquistas.

Pessoas do mundo inteiro viajam em busca de novas experiências com o esporte, tanto como praticantes, como espectadores. Procuram espaços públicos, quadras, campos, parques, outros praticantes, estádios, visitações, museus, lojas de produtos esportivos, e tudo mais que possam fazer para que vivam a experiência do esporte. Segundo Hudson (2003), os atrativos de turismo esportivo são aqueles que proporcionam aos turistas atividades para fazer e ver relacionadas ao esporte, incluindo participantes, espectadores e viajantes. Essas atividades incluem: visitações a estádios e arenas, museus de esportes, lojas de artigos esportivos e eventos esportivos.

De acordo com Pine II e Gilmore (1999), diante de uma realidade cada vez mais complexa - por conta da concorrência acirrada, em que produtos e suas tecnologias podem ser copiados, uma alternativa para que as empresas possam, de fato, competir, é utilizarem-se do quarto nível de oferta econômica, conhecido como "experiência". Sendo assim, o presente artigo teve como objetivo analisar como clubes procuram oferecem a experiência em seus museus e estádios, por meio de visitações (tours), tecnologias, recursos humanos e acervos, para visitantes que buscam algo que mexe com seus sentimentos, paixões e memórias, que são capazes de transmitir uma profunda experiência sensorial e emocional. Para atingir os objetivos propostos, foi utilizada a técnica de observação não participativa nos museus e estádios do Club Atlético Boca Juniors, Sport Lisboa e Benfica, Fútbol Club Barcelona, Real Madrid Club de Fútbol e Maracanã. 


\section{GESTÃO DO FUTEBOL E INTERNACIONALIZAÇÃO DA MARCA}

O futebol movimenta bilhões de dólares por ano com a venda de produtos e serviços, sendo que tal fato se deve a possibilidade de as pessoas terem acesso a qualquer clube do mundo através da televisão, do rádio, de aplicativos de celular e, principalmente, da internet.

Mas nem sempre foi assim. Diversos clubes que reconhecemos como clubes globais, passaram por um processo de transformação. Precisaram encontrar um caminho em que pudesse expor a marca do clube, alavancar patrocínios e fazer com que pessoas do mundo inteiro quisessem consumir mais.

O marketing apareceu com uma ferramenta muito importante nesse processo de expansão mundial e o crescimento dessa fonte de renda culminou na mudança de modelo fundamental, que transforma o negócio dos clubes de futebol em um negócio de entretenimento global (SORIANO, 2010, p. 22).

De acordo com Dunning (1999), os principais motivos que levam uma empresa a se internacionalizar, entre outros, são a atratividade dos mercados globais. Para transcender o mercado local, precisariam encontrar um caminho para mostrar seu produto para o mundo. A televisão e a internet se tornavam os principais meios de comunicação para mostrar as partidas ao vivo. Com a chegada das redes privadas, houve um efeito imediato na briga pelos direitos de transmissão das partidas. O principal objetivo era transformar essa audiência global numa clientela também global.

Existem exemplos de sucessos que podem ser utilizados como benchmarking no que tange à gestão estratégica que vise a expansão dos mercados internacionais, como vemos a seguir.

A prática do benchmarking com empresas de sucesso, pode proporcionar experiências muito significativas, quando tentam dar um passo à frente. Nesse ponto, na Europa, mais precisamente na Inglaterra, tem-se o Manchester United como sinônimo de sucesso quanto a sua gestão estratégica de expansão pelo mundo nos anos 90, pois foi um dos pioneiros na exploração, principalmente, do mercado asiático, levando ao público sua marca, seus jogos e seus produtos (BEZERRA, et al., 2017, p. 6).

Segundo Leoncini e Silva (2002), a discussão dos princípios de gestão usados pelo Manchester United envolve algumas premissas estratégicas oriundas da concepção desta nova missão do clube, que passa, dentre outras, pela maximização de receitas (fruto de sua reputação e de seu desempenho em campo, e do tratamento do torcedor como cliente) e a exploração de seu estádio, construído para gerar receita o ano todo através do que se convencionou chamar de "arena multiuso". Estes exemplos dos pilares do modelo de gestão do clube inglês se traduzem na declaração sucinta de sua estratégia global.

Para Asensio et al. (2012) as entidades museológicas ligadas a sociedades esportivas encontram um intercâmbio entre três conceitos - cultura, turismo e marketing -, que convivem num único espaço de atividades cada um com a sua lógica, se inter-relacionando e propondo uma nova experiência ao torcedor.

As formas de associação encontradas na relação do torcedor com o futebol, como aponta Moreira (2012), ultrapassam o sentido original da palavra "fan", assemelhando-se à participação religiosa e ultrapassando a política e econômica, e são baseadas em liberdade de critérios de escolha do pertencimento e igualdade.

Dessa forma, entende-se que os fatores da paixão, emoção, identificação e da vivência, se bem explorados, podem funcionar como fatores de dinamização de venda dos produtos e serviços oferecidos pelo clube, já que a ideia de produto esportivo teve seu escopo ampliado. Ou seja, incorporando o evento esportivo como um elemento essencial, assim como, tudo aquilo que está envolvido para que ele ocorra, por exemplo, instalações, atletas, materiais e serviços prestados.

Sendo assim, existe um número enorme de apaixonados pelo futebol, pelos seus clubes, e por tudo que diz respeito a eles: ídolos, competições, produtos, serviços, técnica, história, estatísticas, arte, estádios e museus. 


\section{MUSEUS NA ERA DA INFORMAÇÃO E DA EXPERIÊNCIA}

A sociedade passa por um momento de mudanças, principalmente, com o aumento do uso de tecnologias, se tornando cada vez mais exigente, imediatista, comunicativa e com a necessidade de trocar informações constantemente. Assim como a sociedade, "os museus vivem numa fase de transformação, um fértil momento de produção e criatividade, em busca de novos/outros formatos e de uma atualização às demandas atuais” (ISRAEL, 2011, p. 19). Estão objetivando oferecer experiências, um sentimento de aprendizado, conhecimento e valor, que perdurará na memória por mais tempo. Os museus são uma espécie de pequenasimensas janelas onde as pessoas, no presente, observam o universo, na forma de lugares, tempos e diferentes culturas. "Ele aproxima as pessoas, mesmo que não vivam nos mesmos lugares não falem a mesma língua e sequer estejam no mesmo tempo" (BITTENCOURT, 2009, p. 21).

Entende-se que existem tipos e conceituações acerca dos museus: uns são feitos apenas para serem observados e contemplados, através de seus objetos e artes. Outros são voltados para a área educacional, preocupados com emitir teorias, fatos históricos e em abundar o visitante com cultura, instrução, conhecimento e crítica (COSTA, 2015).

Existem também os chamados museus interativos, que de acordo com Souza e Alves (2011), além de apresentarem suas histórias e coleções, buscam interagir com os visitantes e torná-los participativos no processo de aprendizagem e conhecimento, a fim de gerar uma nova experiência para o visitante. São, geralmente, espaços dinâmicos que usufruem da tecnologia multimídia, de cores e sons, e formas bastante diversificadas. Além de funcionar como ferramenta de marketing e atração de visitantes locais e turistas.

Museus interativos atravessam um momento de redefinição, de experimentar novas possibilidades e testar outros limites.

Recriar e atualizar os modelos de espaços culturais significa repensar a dinâmica da informação, a fluidez das narrativas, o desenvolvimento da tecnologia como espaço para o lúdico, a relação com o consumo e a necessidade de cumprir papéis educacionais e sociais (ISRAEL, 2011, p. 2).

Goulding (2000) aborda a experiência como um processo mediado por um número de aspectos sócio culturais, cognitivos, psicológicos, condições físicas e ambientais de forma interligada. Por isso, a experiência do visitante se relaciona com percepções pessoais e ambientais dos mesmos, englobando uma série de fatores. Para Pine II e Gilmore (1999), a oferta de experiência acontece quando uma instituição usa intencionalmente os serviços como um palco e os produtos como suporte para atrair os consumidores de forma a criar um acontecimento memorável.

Acompanhando as demandas por experiências cada vez mais impactantes, clubes tendem a estruturar seus serviços de visita a museu e estádios, como locais de entretenimento, de identidade e memória, onde o público tem relevante importância, assim como seu acervo. "Na tentativa de dinamizar seus canais expositivos e comunicativos, alguns clubes têm utilizado novas tecnologias de informação baseadas na interatividade e no virtual” (BARBOSA; PORTO; MARTINS, 2013, p. 2). “A interação entre instituição e público potencializa a imersão” (CARVALHO, 2008, p. 89) dentro do ambiente ativando a percepção e o cognitivo.

A tecnologia precisa ser entendida como fonte de inovação, diferenciação estratégica e vantagem competitiva para a cocriação bem-sucedida de experiências no futuro, já que múltiplos níveis de engajamento e redes de interação permitem mais rica e personalizada experiência e valor distinto para as pessoas" (SILVA; MENDES FILHO, 2016, p.1).

Esta crescente dependência do mercado de produtos e serviços nas Tecnologias da Informação, nasce da necessidade de adaptar-se ao novo comportamento dos consumidores. Pode-se observar a persistente imersão do homem moderno no ambiente digital. Trata-se de um homem que cria, absorve, compartilha, opina, avalia, curte e apaga todo o tipo de informação a cada minuto. "Esta revolução tecnológica e social foi possibilitada graças à criação da Internet no início dos anos 80 e tomou proporções gigantescas nos últimos anos com a criação das tecnologias móveis" (PAFFRATH; CASSOL, 2014, p. 429). 
No momento pós compra de um produto ou serviço, os consumidores compartilham suas experiências, reforçando umas das principais utilidades da internet que é permitir que qualquer um seja criador de conteúdo. "Redes sociais como Facebook, Youtube, Twitter ou Flickr utilizam um ambiente para interagir, comentar e partilhar suas experiências individuais e construir um ambiente comunitário" (NEUHOFER; BUHALIS; LADKIN, 2012, p. 41). "O que tem poder persuasivo, já que trata da opinião perspectiva dos compradores" (AYEH; AU; LAW, 2013, p. 447).

Para Del Chiappa, Andreu e Gallarza, (2014), os clubes começaram a utilizar tecnologias de informação e comunicação, como mídias sociais e smartphones para tentar evitar que a visita se torne entediante principalmente entre os visitantes mais jovens, acenando para um acompanhamento da nova demanda por experiências mais inovadoras e contemporâneas. Pensando em formas de divulgação instantânea e promoção do local mais do que um mantenedor de memórias e objetos, Moreira (2012) acredita que o museu, além de seu trabalho na preservação do patrimônio material e imaterial do clube e dos sócios, pode e deve assumir suas funções como equipamento cultural e turístico da cidade. Basta ter uma compreensão clara do que significam, das suas peculiaridades e potencialidades.

\section{TURISMO ESPORTIVO}

O turismo motivado pelo esporte, ou o ato de se viajar por razóes relacionadas ao esporte, começa a ser tratado como atividade turística a partir da popularização, a nível mundial, das competiçóes esportivas. $\mathrm{O}$ rápido crescimento do segmento como afirma Ribeiro (2014) está relacionado a uma série de fatores como a democratização do esporte, o investimento em infraestruturas esportivas, além do crescimento da oferta turística e às diversas opções de mobilidade existentes.

Beni (2001), define o turismo esportivo como o deslocamento de turistas aficionados das distintas modalidades de esportes, que afluem a núcleos esportivos tradicionais com calendário fixo de eventos ou a núcleos que eventualmente sediem olimpíadas, competições e torneios. Nesse caso, o principal produto turístico é o esporte.

Carvalhedo (2003) aponta o turismo esportivo como uma viagem com fins recreativos nas quais os indivíduos participam de atividades físicas, assistem a eventos esportivos ou visitam atrações associadas a atividades esportivas. Tais atividades segundo Ross (2001) e Carvalhedo (2003) podem ser resumidas em três tipos de comportamentos associados ao turismo esportivo: turismo esportivo ativo; turismo esportivo de eventos; e turismo esportivo de visita (a estádios e museus de esportes são alguns exemplos). Quanto ao turismo esportivo de visita, Ross (2001) entende, na verdade, que esse seria o turismo esportivo nostálgico, pois está relacionado à busca pelo passado, como museus, hall da fama, dentre outros.

O tema desse trabalho recai sobre as atividades relacionadas a visitação de estádios e museus, por conta de seu crescimento em países que tem o futebol muito popular e, principalmente, pelo potencial retorno financeiro.

Segundo Arantes (2015), o museu localizado no estádio Camp Nou, do Barcelona, recebeu em 2014, 1,5 milhão de pessoas, com um faturamento de 27 milhões de euros (118 milhões de reais, no câmbio da época). Já o do Real Madrid, no mesmo período, recebeu cerca de 920 mil visitantes, com faturamento próximo de 17,5 milhões de euros (76 milhões de reais, no câmbio da época). Já para Porta (2016), no período entre 01 de julho de 2014 e 30 de junho de 2015, o tour do estádio do Real Madrid com a visita ao seu museu (Tour do Bernabéu) recebeu mais de 1 milhão de visitantes, sendo cerca de 55\% estrangeiros, com 70\% europeus e $30 \%$ do resto do mundo.

A ampla cobertura da mídia, principalmente pela televisão e internet, fez com que pessoas do mundo inteiro, tivessem maior acesso aos seus esportes preferidos, principalmente o futebol. Essa aproximação fez com que os dirigentes dos clubes percebessem que mais do que assistir aos jogos e torcer, essas pessoas querem vivenciar toda a experiência. 
Para Pezzi e Vianna (2015), o turista atual não se satisfaz em apenas contemplar atrativos turísticos e conhecimentos superficiais, mas quer também adquirir conhecimentos mais intensos e profundos dos lugares que visitam. Cidadãos consumidores de entretenimento tendem a se conectar às experiências mais relevantes e que estejam alinhadas com seu estilo de vida e definem determinadas experiências de consumo como representantes de algo mais do que experiências aparentemente comuns de consumo, conforme Hiller (2011).

No caso do futebol, museus e, principalmente, estádios, dão a possibilidade aos amantes do esporte de terem a experiência de entrar em locais inacessíveis em dias de jogos, onde seus ídolos passaram e deixaram sua marca, conquistando suas vitórias e moldando toda a história. Poder estar em contato dessa maneira, faz com que o visitante possa explorar o máximo de sua imaginação e reviver momentos marcantes em sua memória.

Para Rieunier (2004 apud ALMEIDA, 2013), a crescente utilização do marketing experiencial ou sensorial é devido à intensa concorrência entre as empresas, que impulsiona o surgimento de novas formas de organização do espaço comercial, com vistas a atender às necessidades e aos desejos dos consumidores que querem vivenciar experiências de compra e consumo prazerosas.

\subsection{Atrativo Turístico}

Para Beni (1998) e Oliveira (2005), atrativo turístico é tudo aquilo de interesse turístico, lugar, objeto ou acontecimento, que motiva o deslocamento de pessoas para conhecê-los. Por exemplo, a Torre Eiffel em Paris ou Coliseu em Roma e, até mesmo, megaeventos como as Olimpíadas e a Copa do Mundo. Para Bahl (2004), os atrativos turísticos constituem o componente principal e mais importante do produto turístico. É considerado como elemento básico para a determinação turística de uma localidade. No mais, torna-se o referencial do próprio local onde estão localizados ou se manifestam.

O principal componente para realizar uma boa experiência passa por uma comunicação eficaz, onde os interessados em visitar tenham fácil acesso a informações sobre tudo que envolve o atrativo, como ter um site oficial, dispondo sobre produtos e serviços oferecidos, preços, horários de funcionamento, localização, orientação para chegar ao local, compras e/ou reservas online, outros idiomas além do local, entre outros. Clubes de fama global entendem que seus serviços de museus e estádios são atrativos de suas cidades sede e assim, investem em marketing para a divulgação em sites e redes sociais de grande apelo no âmbito do turismo. Assim, toda a demanda de turista que acessa esses sites pode ter conhecimento sobre a oferta e a experiência e partir disso se programam para usufruir tais produtos.

\section{METODOLOGIA}

A natureza da pesquisa é caracterizada como qualitativa, pois como afirma Gil (1999) esse tipo de pesquisa propicia o aprofundamento da investigação das questões relacionadas ao fenômeno em estudo e das suas relações. Na concepção de Creswell (2007) a pesquisa qualitativa é fundamentalmente interpretativa. Segundo Triviños (1987), a abordagem de cunho qualitativo trabalha os dados buscando os significados, tendo como base a percepção do fenômeno dentro do seu contexto.

A pesquisa tem cunho exploratória, que, segundo Selltiz, Wrightsman e Cook (1965), são todos aqueles estudos que buscam descobrir ideias e intuições, na tentativa de adquirir maior familiaridade com o fenômeno pesquisado. Para Zikmund (2000), os estudos exploratórios, geralmente, são úteis para diagnosticar situações, explorar alternativas ou descobrir novas ideias.

Os objetos de pesquisa foram estádios e museus esportivos de clubes com renome no cenário internacional, possibilitados pela oportunidade e acesso que os pesquisadores tiveram em relação ao deslocamento até o campo de pesquisa. 
Quanto aos procedimentos, foi adotado a pesquisa de campo, que segundo Fonseca (2002), se caracteriza por investigações em que, além da pesquisa bibliográfica e/ou documental, se realiza coleta de dados junto à pessoas, com o recurso de diferentes tipos de pesquisa.

No presente estudo, a técnica de coleta de dados utilizada foi a observação não participativa, que segundo Godoy (1995), o pesquisador atua como espectador atento integralmente apenas às ocorrências consideradas interessantes.

Para atingir o objetivo proposto, foram realizadas visitas a quatro museus e tour em cinco estádios, entre os anos de 2015 e 2017, com o intuito de observar e analisar quais fatores impactam diretamente na experiência de visitação. Entre os focos de observação: utilização e aproveitamento da estrutura do clube, disponibilidade de informações, da qualidade do roteiro, das tecnologias utilizadas e forma de interação com os visitantes. Os locais de pesquisas foram: Museus - Boca Juniors (Argentina), Barcelona e Real Madrid (Espanha), Benfica (Portugal). Tour em estádios - Boca Juniors (Argentina), Barcelona e Real Madrid (Espanha), Benfica (Portugal) e Maracanã (Brasil)

Assim, para que pudesse analisar a disponibilidade de tecnologias, recursos humanos e acervos, para proporcionar uma experiência única ao visitante, foi criada uma avaliação moldada para os museus e estádios, em que se pudesse evidenciar a capacidade. Foi utilizada como inspiração a proposta de Schimitt (2000 apud GOSLING et al., 2016), que buscou a compreensão da problemática relacionada à experiencia do consumidor a partir de cinco dimensões: 1) experiências sensoriais (sentidos); 2) experiências afetivas e emoções (sentimento); 3) experiências de criatividade cognitivas (pensamento); 4) experiências físicas, comportamentos e estilos de vida (ação); 5) experiências de identidade social (relacionar-se). A análise dos dados obtidos foi realiada através da análise de conteúdo, que para Bardin (2011) designa:

Um conjunto de técnicas de análise das comunicações visando a obter, por procedimentos sistemáticos e objetivos de descrição do conteúdo das mensagens, indicadores (quantitativos ou não) que permitam a inferência de conhecimentos relativos às condições de produção/recepção (variáveis inferidas) destas mensagens (BARDIN, 2011, p. 47).

A partir disso, "entendendo a experiência do consumidor como uma avaliação multidimensional e holística” (GOSLING et al., 2016, p. 111), foram elaboradas avaliações dividas em áreas compostas de variáveis, ou categorias de análise, conforme abaixo:

a) Visitação - verificar nas visitas aos estádios e museus se esses possuem visita guiada, áudio guia, um roteiro definido, além de informações em outros idiomas que não o local;

b) Museu - analisar a exposição de troféus, camisas históricas, interatividade com títulos, vídeos, áudios de gols e/ou torcida, estátuas de ídolos e experiências sensoriais.

c) Estádio - verificar se possuíam acesso ao vestiário, arquibancadas, gramado e sala de imprensa.

d) Interatividade - verificar a disponibilidade de tecnologia para postagem direta em mídias sociais, fotos virtuais com os jogadores, realidade virtual aumentada. Além de oferta de ações com jogadores e ex-jogadores para participação e interação na visita.

e) Informações e compra - verificar se possuíam site oficial, citação em locais físicos de turismo da cidade, compra online, site com disponibilidade em outros idiomas, citação em sites oficiais de turismo.

Para alcançar uma base teórica, que embasasse todo nosso trabalho, foi utilizada a técnica de pesquisa bibliográfica, que segundo Vergara (2000), é desenvolvida a partir de material já elaborado, constituído, principalmente, de livros e artigos científicos. Importante etapa para o levantamento de informações básicas sobre os aspectos direta e indiretamente ligados à nossa temática. Assim, foram utilizadas múltiplas fontes de informações, como sites oficiais dos clubes e instituições, reportagens, artigos acadêmicos e livros. 


\section{RESULTADOS E ANÁLISES}

Nesse capítulo estão dispostas a apresentação dos resultados e suas análises. Para a mehor compreensão o capítulo foi dividido em duas seções: museus e tour de estádios. Dentro de cada uma das seções há um quadro onde estão apresentadas as áreas de avaliação, elaboradas conforme os critérios detalhados na seção anterior. Após os quadros estão as análises mais detalhadas de cada área.

\section{1) Museus}

\section{QUADRO 1}

Avaliação Multidimensional dos Museus Visitados

\begin{tabular}{|c|c|c|c|c|c|}
\hline Áreas & Itens & Boca Juniors & $\begin{array}{l}\text { Real } \\
\text { Madrid }\end{array}$ & Barcelona & Benfica \\
\hline \multirow{4}{*}{ Sítio oficial } & Possui site próprio? & $\mathrm{X}$ & $\mathrm{X}$ & $\mathrm{X}$ & $\mathrm{X}$ \\
\hline & $\begin{array}{l}\text { Site turismo oficial da } \\
\text { cidade }\end{array}$ & $\mathrm{x}$ & $\mathrm{X}$ & $\mathrm{x}$ & $\mathrm{x}$ \\
\hline & $\begin{array}{l}\text { Está disponivel em outros } \\
\text { idiomas? }\end{array}$ & & $\mathrm{x}$ & $\mathrm{x}$ & $\mathrm{x}$ \\
\hline & $\begin{array}{l}\text { Possibilidade de compra } \\
\text { online? }\end{array}$ & & $\mathrm{x}$ & $\mathrm{X}$ & $\mathrm{X}$ \\
\hline \multirow{4}{*}{ Visitação } & Visita guiada & & $\mathrm{x}$ & $\mathrm{X}$ & $\mathrm{X}$ \\
\hline & Áudio Guia & & & $\mathrm{X}$ & \\
\hline & Roteiro definido & $\mathrm{X}$ & $\mathrm{X}$ & $\mathrm{X}$ & $\mathrm{X}$ \\
\hline & Outros idiomas disponiveis & & $\mathrm{X}$ & $\mathrm{X}$ & $\mathrm{X}$ \\
\hline \multirow{7}{*}{$\begin{array}{l}\text { Itens dos } \\
\text { acervos dos } \\
\text { museus }\end{array}$} & Troféus & $\mathrm{X}$ & $\mathrm{X}$ & $\mathrm{X}$ & $\mathrm{X}$ \\
\hline & Camisas históricas & $\mathrm{X}$ & $\mathrm{X}$ & $\mathrm{X}$ & $\mathrm{X}$ \\
\hline & Interatividade com títulos & & $\mathrm{X}$ & & $\mathrm{X}$ \\
\hline & Vídeos "históricos" & $\mathrm{X}$ & $\mathrm{X}$ & $\mathrm{X}$ & $\mathrm{X}$ \\
\hline & Áudio de gols e torcida & $\mathrm{X}$ & $\mathrm{X}$ & & $\mathrm{X}$ \\
\hline & Estátuas & $\mathrm{X}$ & & & $\mathrm{X}$ \\
\hline & Experiências sensoriais & $\mathrm{X}$ & $\mathrm{X}$ & & \\
\hline \multirow{5}{*}{ Interatividade } & Postagem em Mídia Social & & $\mathrm{X}$ & $\mathrm{X}$ & $\mathrm{X}$ \\
\hline & Foto virtual com jogadores & & $\mathrm{X}$ & $\mathrm{X}$ & \\
\hline & $\begin{array}{l}\text { Realidade virtual } \\
\text { aumentada }\end{array}$ & & & & \\
\hline & $\begin{array}{l}\text { Ação com jogadores ou } \\
\text { ex-jogadores }\end{array}$ & & & & \\
\hline & Loja Oficial & $\mathrm{X}$ & $\mathrm{X}$ & $\mathrm{X}$ & $\mathrm{X}$ \\
\hline
\end{tabular}

Adaptado de Schimitt (2000 apud GOSLING et al., 2016)

\section{a) Sítio oficial}

Todos os clubes possuem uma página eletrônica oficial para seus museus, com informações relevantes sobre horários de funcionamento, endereço, resumo sobre o conteúdo do museu, além de valores de ingressos. A possibilidade de compra online e a disponibilidade de leitura em outros idiomas, além do local, está disponível apenas no Real Madrid, Benfica e Barcelona, o que reforça a preocupação dos clubes em se comunicar com turistas de outros países, sendo considerada uma vantagem competitiva.

O fato de serem considerados atrativos turísticos de suas cidades pôde ser confirmado, já que todos os museus foram mencionados nas páginas oficias de turismo de sua respectiva cidade ${ }^{1}$.

b) Visitação

Nesse item destacou-se quatro elementos que podem interferir diretamente na experiência da visita: (i) tour guiado, (ii) possuir áudio guia, (iii) disponibilidade de informações em outros idiomas e (iv) possuir um roteiro definido. 
A visita guiada foi encontrada nos museus do Benfica, Real Madrid e Barcelona, sendo que nos dois últimos, apenas com a compra de ingressos especiais, o que traz uma experiência diferente dos outros clubes, por criar uma interação maior com o acervo disponível.

Outro item importante é a possibilidade de se usar um áudio guia para se obter informações mais detalhadas sobre o acervo e a história do clube. Nesse ponto, somente o Barcelona oferecia tal serviço. Como o fluxo de estrangeiros por esses locais é bem grande, seria um fator diferencial para melhoria da experiência dos visitantes, além da capacidade de se relacionar com o exposto.

Nessa mesma linha, Barcelona, Benfica e Real Madrid dispunham de informações escritas em outros idiomas próximos a peças e fotos históricas, item que o Boca Juniors deixou de investir. Ter um roteiro definido faz com que o clube possa trabalhar a experiência dos visitantes em uma ordem mais interessante e mais completa, passando por todos os fatos históricos do clube, seus ídolos e as conquistas de maior relevância, buscando causar um impacto positivo nos visitantes e uma compreensão melhor de sua história, e isso é percebido pelos gestores dos museus dos clubes analisados, já que todos eles apresentam um roteiro bem definido.

c) Itens do acervo nos museus

O produto mais relevante dentro de um museu são as peças expostas, assim como vídeos e áudios que façam com que os visitantes possam entender e reviver momentos marcantes na história do expositor, ativando suas emoções e sentimentos em relação ao clube. Assim, destacamos itens que compóem essa vertente para o futebol.

Em todos os clubes, observou-se uma ampla mostra de troféus de grandes conquistas, exposição de camisas históricas, além de vídeos contando fatos marcantes. Ainda, disponibilizam áudios de torcidas e/ou narrações de gols. Estátuas também puderam ser vistas no clube argentino e no português, valorizando a imagem de seus ídolos, como Maradona e Eusébio.

A presença de tecnologia para que existisse uma maior interação com a história e as conquistas, foram verificadas nos museus de Real Madrid e Benfica, que ofereciam telas sensíveis ao toque, para que os torcedores possam acessar os títulos e os gols de jogos memoráveis. Em Madrid, ainda se encontrou um espaço destinado a uma tecnologia na qual se podia escutar os cantos da torcida no estádio. O do Boca Juniors, oferece uma experiência única dentro de um cinema $360^{\circ} \mathrm{em}$ formato de bola de futebol, na qual os visitantes entram e tem a sensação de estarem em campo durante a partida do time, sentindo a atmosfera da torcida e tendo a visão que o jogador tem, em todos os ângulos. Experiências sensoriais como estas, tornam-se vantagens competitivas dentro da rede de entretenimento disponíveis em suas cidades sede.

d) Interatividade

Os três clubes europeus utilizam uma ferramenta de postagem de foto em redes sociais ao longo do percurso no museu. Isso reforça a interação das pessoas com o local, mostrando instantaneamente aos seus amigos onde estão, além de ser uma excelente fonte de propaganda para o clube. Os espanhóis ainda apostam em uma tecnologia para fotos virtuais com seus jogadores favoritos, como Messi e Cristiano Ronaldo.

Dois itens explorados em outras localidades e valorizados pela literatura atual, que não foram encontrados em nenhum dos quatro museus visitados, foi a tecnologia de realidade virtual aumentada, onde os visitantes usam óculos que simulam a entrada em campo com os jogadores, o passeio pelas arquibancadas em dia de jogos, além de vestiários, por exemplo. O outro, foi a oferta de ações com jogadores atuais ou ex jogadores, que poderiam fazer com que a experiência de explorar o museu fosse ainda mais gratificante, já que os atletas fizeram parte da construção das conquistas do clube. Vale ressaltar que clubes e entidades no Brasil já realizaram ações de sucesso nesse sentido, como o museu da Seleção Brasileira, no Rio de Janeiro e o Tour do São Paulo Futebol Clube.

e) Loja oficial

Ao final de todas as visitas, existem lojas oficiais com uma grande oferta de produtos. Nelas os visitantes podem encontrar todo o tipo de produtos licenciados pelo clube, o que se torna um marketing forte, já que 
as pessoas acabaram de finalizar uma imersão na história do clube. O sentimento e a emoção vivida podem se tornar grandes incentivadores do consumo naquele momento.

2) Estádios

QUADRO 2

Avaliação Multidimensional dos Tours nos Estádios Visitados

\begin{tabular}{|c|c|c|c|c|c|c|}
\hline Áreas & Itens & Maracanã & \begin{tabular}{|l} 
Boca \\
Juniors
\end{tabular} & $\begin{array}{l}\text { Real } \\
\text { Madrid }\end{array}$ & Barcelona & Benfica \\
\hline \multirow{4}{*}{ Sítio oficial } & Sítio próprio & & $\mathrm{X}$ & $\mathrm{X}$ & $\mathrm{X}$ & $\mathrm{X}$ \\
\hline & $\begin{array}{l}\text { Sítio oficial de turismo } \\
\text { da cidade }\end{array}$ & $\mathrm{X}$ & $\mathrm{X}$ & $\mathrm{X}$ & $\mathrm{X}$ & $\mathrm{X}$ \\
\hline & $\begin{array}{l}\text { Disponibilidade em } \\
\text { outros idiomas } \\
\end{array}$ & & & $\mathrm{X}$ & $\mathrm{X}$ & $\mathrm{X}$ \\
\hline & Compra Online & $\mathrm{X}$ & & $\mathrm{X}$ & $\mathrm{X}$ & $\mathrm{X}$ \\
\hline \multirow{4}{*}{ Visitação } & Visita guiada & $\mathrm{X}$ & $\mathrm{X}$ & $\mathrm{X}$ & $\mathrm{X}$ & $\mathrm{X}$ \\
\hline & Áudio Guia & & & & $\mathrm{X}$ & \\
\hline & Roteiro definido & $\mathrm{X}$ & $\mathrm{X}$ & $\mathrm{X}$ & $\mathrm{X}$ & $\mathrm{X}$ \\
\hline & Outros idiomas & $\mathrm{X}$ & & $\mathrm{X}$ & $\mathrm{X}$ & $\mathrm{X}$ \\
\hline \multirow{4}{*}{$\begin{array}{l}\text { Itens de } \\
\text { avaliação } \\
\text { dos } \\
\text { estádios }\end{array}$} & Vestiário & $\mathrm{X}$ & $\mathrm{X}$ & $\mathrm{X}$ & $\mathrm{X}$ & $\mathrm{X}$ \\
\hline & Arquibancadas & $\mathrm{X}$ & $\mathrm{X}$ & $\mathrm{X}$ & $\mathrm{X}$ & $\mathrm{X}$ \\
\hline & Gramado & $\mathrm{X}$ & $\mathrm{X}$ & $\mathrm{X}$ & $\mathrm{X}$ & $\mathrm{X}$ \\
\hline & Sala de imprensa & $\mathrm{X}$ & $\mathrm{X}$ & $\mathrm{X}$ & $\mathrm{X}$ & $\mathrm{X}$ \\
\hline
\end{tabular}

Adaptado de Schimitt (2000 apud GOSLING et al., 2016)

\section{a) Sítio oficial}

Os sites que possuem as informações sobre os museus são os mesmos para os tours, com exceção do estádio do Maracanã que não possui uma página oficial, tendo apenas a venda online através de um sítio de ingressos gerais, o ingressocerto.com.br. Na mesma linha de investigação, confirmou-se que os mesmos sítios eletrônicos oficiais de turismo das cidades, referenciam a visitação de estádios ${ }^{2}$.

b) Visitação

Quanto à visita guiada, é oferecida no estádio do Maracanã (nos idiomas português e inglês), do Boca Juniors (apenas no idioma espanhol) e do Benfica (nos idiomas português e inglês). Os demais clubes permitem a contratação do serviço mediante a compra de ingressos especiais ou em grupo. O serviço de áudio guia é oferecido apenas no estádio do Barcelona. Além disso, todos possuem sinalizações evidentes para que um roteiro seja realizado sequencialmente e a experiência proposta possa ser cumprida.

c) Itens de avaliação dos estádios

Todos os locais pesquisados oferecem visitas a arquibancadas, sala de imprensa e coletivas, vestiários e gramado de jogo, sendo as duas últimas opções, as preferidas dos torcedores. Entende-se que essa preferência se dê por serem os locais onde os atletas vivem e os torcedores não podem estar nos dias de jogos.

Além disso, os clubes apresentavam vestiários personalizados para os jogadores, trazendo mais uma nova experiência de poder estar exatamente onde seus jogadores preferidos ficam durante um dia de jogo. A ida ao gramado é considerado como um dos pontos de maior relevância e destaque, pois os torcedores têm vontade de estar e sentir como é pisar no gramado de um campo oficial de jogo e "encarar" as arquibancadas.

Nesse aspecto todos os tours permitem aos torcedores uma nova perspectiva quanto a experiência de jogo, passando exatamente por onde os protagonistas estão, trazendo à memória histórias que foram vividas por muitos nas arquibancadas daqueles mesmos estádios. Essa forma de fazer o visitante experimentar essas sensações fazem os tours terem uma vantagem grande para o seu público apaixonado. 


\section{CONCLUSÕES E RECOMENDAÇÕES}

Concluiu-se que os clubes e estádios descritos no presente artigo, tratam seus museus e estádios como mais do que espaços reservados a memória, todos buscam oferecer uma experiência diferente para seus visitantes, através do uso de tecnologias, tais como vídeos e sons, além das emblemáticas peças históricas, como chuteiras, camisas e troféus, ativando seus sentimentos e emoções. Isso se torna fundamental quando é percebido o movimento que ocorre na disciplina museológica e turística, para modernizar e tornar os museus em espaços de aprendizado e atrativos de suas cidades, mas isso sendo feito por uma nova perspectiva, onde sentimentos e emoções farão com que seu público tenha mais interesse em visitá-los.

Como forma de gerir as novas realidades do mercado cultural, turístico e esportivo, os clubes e entidades que querem se tornar referência nacional e internacional de entretenimento, devem se planejar e entender as formas de se relacionar com seu público em potencial.

A cultura da inovação está presente em todos os casos de sucesso envolvendo o entretenimento, principalmente, através da geração de experiências, já que os estados emocionais e sentimentais são coproduzidos pelos clubes e pelo público. Além disso, a importância da gestão dos espaços dedicados ao esporte, tanto os museus quanto os tours dos estádios, para transformá-los em atrativos turísticos de suas cidades sede é um fato a se destacar. Cada vez mais estes locais vem ganhando força e atraindo mais pessoas, se tornando muitas vezes como fator decisivo de escolha dos destinos dos viajantes. Conforme apresentado anteriormente, casos como o do Real Madrid e Barcelona, recebem mais de 1 milhão de visitantes por ano.

Entende-se assim que os clubes que têm a intenção de se internacionalizar e se tornarem atrativos turísticos de suas cidades, partem para trazerem para seu público alvo uma interação maior através de seu sítio oficial e as redes sociais, assim buscando atrai-los para consumir seus produtos e serviços, além de estimulá-los a fazer parte fisicamente da história do clube.

Dessa maneira, é possível concluir que a gestão dos museus e dos tours de estádios estão se tornando cada vez mais relevantes nessa busca de oferecer uma nova experiência, além do jogo de futebol em si, para os visitantes, apresentando novas emoções por novas perspectivas, gerando novas fontes de receitas e fidelização para os clubes de futebol, assim como atração de turistas para as respectivas cidades sede.

\section{ReFERENCIAS}

ALMEIDA, K. P. R. O uso de elementos sensoriais no ponto de venda aumenta os índices de atratividade, lealdade e preferência dos shoppers à loja?: uma reflexão crítica. 2013. 79 p. Dissertação (Mestrado em Administração) - Pontifícia Universidade Católica de São Paulo, São Paulo, 2013.

ASENSIO, M.; IBANEEZ, A.; CALDERA, P.; ASENJO, E.; CASTRO, Y. Gestión de Colecciones: documentación y conservación. Madrid: Series de Investigación Iberoamericana de Museología. 2012.

ARANTES, Thiago. Nos museus, Barcelona ganha fácil do Real Madrid. Disponível em: http://espn.uol.com.br/ noticia/550822_nos-museus-barcelona-ganha-facil-do-real-madrid. Acesso em: 16 de julho de 2017.

AYEH, Jullian; AU, Norman; LAW, Rob. Do we believe in TripAdvisor? examing credibility perceptions and online travelers' atitude toward using user-generated contente. Journal of Travel Research, v. 52, n. 4, fev, 2013

BAHL, Miguel. Legados Étnicos \& Ofertas Turísticas. Curitiba: Juruá. 2004.

BARBOSA, C. R..; PORTO, R. M. A. B.; MARTINS, C. E. M. A. Museus: sistemas de informação para uma realidade virtual. ENCONTRO NACIONAL DE PESQUISA EM CIÊNCIA DA INFORMAÇĀO. Rio de Janeiro-RJ, 2013. Disponível em < http://enancib.ibict.br/index.php/enancib/xiiienancib/paper/viewFile/3924/3047> Acesso em: 26 abr, 2019.

BARDIN, L. Análise de conteúdo. São Paulo: Edições 70. 2011

BENI, M. Análise Estrutural do Turismo (5a. ed.). São Paulo, SP: SENAC. 2001. 
BEZERRA, M. F.; FEITOSA, P. R.; GOMES, J. S. Internacionalização De Clubes De Futebol: Paralelo Entre Clubes Europeus E Brasileiros. Revista Iberoamericana de Contabilidad de Gestión, v. XV, n.30, julio-deciembre, 2017.

BITTENCOURT, J. N. As coisas dentro da coisa: observações sobre museus, artefatos e coleções. In: AZEVEDO, Flávia Lemos Mota de; PIRES, João RIcardo Ferreira; CATÂO, Leandro Pena. (Org.). Cidadania, Memória e Patrimônio: As dimensões do museu no cenário atual.. 1ed.Belo Horizonte: Crisálida, 2009, v. 1, p. 1-212.

BUENOS AIRES CIUDAD. Web Oficial de Turismo de Buenos Aires. Disponível em: https:// turismo.buenosaires.gob.ar/es . Acesso em: 26 de julho de 2017.

CARSON, M. Os campeões: por trás da mente dos grandes líderes do futebol. São Paulo: Belas-Letras, 2015.

CARVALHEDO, A. Tourism as a cultural legacy of the Olympic games". In: SYMPOSIUM OF THE INTERNATIONAL CHAIR IN OLYMPISM - LEGACY OF THE OLYMPIC GAMES - 1984/2000, 5. Anais... 2002, Barcelona. Disponível em: < https://library.olympic.org/Default/doc/SYRACUSE/68159/the-legacy-of-the-olympic-games-1984-2000international-symposium-lausanne-14th-15th-and-16th-novemb?_lg=en-GB>

CARVALHO, R. M. R. Comunicação e informação de museus na Internet e o visitante virtual. Museologia e Patrimônio. v.1, n. 1., 2008.

CIDADE DE LISBOA. Turismo de Lisboa. Disponível em: www.visitlisboa.com. Acesso em: 26 de julho de 2017.

CIDADE DO RIO DE JANEIRO. Visit Rio. Disponível em: ww.visit.rio.br. Acesso em: 26 de julho de 2017.

CIUDAD DE BARCELONA. Visit Barcelona. Disponível em: http://www.barcelonaturisme.com/wv3/es/ page/96/museos-deportivos.html. Acesso em: 26 de julho de 2017.

CIUDAD DE MADRID. Web Oficial de Turismo de Madrid. Disponível em: https://www.esmadrid.com/pt . Acesso em: 26 de julho de 2017.

CLUB ATLÉTICO BOCA JUNIORS. Museo de La Passion Boquense. Disponível em: http:// www.museoboquense.com/museo-boquense.php. Acesso em: 26 de julho de 2017.

COSTA, T. C. Museu Do Futebol: A Museografia Como Arte e Diversão. Semana de Extensão, Pesquisa e Pós-Graduação, 11, - Centro Universitário Ritter dos Reis, p. 1-12, 2015. Disponível em: < https:// www.uniritter.edu.br/files/sepesq/arquivos_trabalhos/3612/733/1413.pdf>

CRESWELL, J. W. Projeto de pesquisa: métodos qualitativo, quantitativo e misto (2. Ed). - Porto Alegre: Artmed, 2007.

DEL CHIAPPA, G.; ANDREU, L.; GALLARZA, M. G. Emotions and visitors' satisfaction at a museum. International Journal of Culture, Tourism and Hospitality Research, v.8, n. 4, p. 420-431, 2014.

DUNNING, J. H. Multinational Enterprises and the Global Economy. Inglaterra: Addison-Wesley. 1999.

FONSECA, J. J. S. Metodologia da pesquisa científica. Fortaleza: UEC. 2002.

FUTBOL CLUB BARCELONA. Camp Nou Experience. Disponível em: https://www.fcbarcelona.com/tour/buytickets. Acesso em: 26 de julho de 2017.

GIL, A. C. Métodos e técnicas de pesquisa social (5a. ed.). São Paulo: Atlas. 1999.

GODOY, A. S. Pesquisa qualitativa - tipos fundamentais. Revista de Administração de Empresas, v. 35, n. 3, p. 20 -29. 1995.

GOSLING, M. S., SILVA, J. A., MENDES, J., COELHO, M. F.; BRENER, I. Experiência turística em museus: percepções de gestores e visitantes. Tourism \& Management Studies, v. 12, n. 2, p. 107-116, 2016.

GOULDING, C. The Museum Environment and the Visitor Experience. European Journal of Marketing, v. 34, n. 3, p. 261-278, 2000.

HILLER, M. Uma experiência Estética e de Marketing em Museus. In: CONGRESSO INTERNACIONAL EM COMUNICAÇÃO E CONSUMO. Anais... 2011, São Paulo. Disponível em: < http://marcoshiller.com.br/ artigos/uma-experiencia-estetica-e-de-marketing-nos-museus-modernos/>.

HUDSON, S. Sports and Adventure Tourism. New York: The Haworth Hospitality Press. 2003. 
ISRAEL, K. P. Informação e tecnologia nos museus interativos do contemporâneo. 18p. Trabalho de conclusão do curso (Pós-graduação em Cultura, Mídia e Informação) - Universidade de São Paulo, São Paulo, 2011. Disponível em: < http://paineira.usp.br/celacc/?q=pt-br/celacc-tcc/253/detalhe>

LEONCINI, M. P.; SILVA, M. T. Analisando a Indústria do Futebol e suas Dinâmicas: Quais as Forças que Empurram os Clubes de Futebol Rumo a Profissionalização de suas Atividades. Gestão e Produção. São Carlos. v. 12, n. 1, p. 1-20, jan-abr 2002.

MARQUES, R. F. R. Esporte e Qualidade de Vida: reflexão sociológica. 159p. Dissertação (Mestrado em Educação Física) - Universidade Estadual de Campinas - UEC, Campinas, 2007. Disponível em: repositorio.unicamp.br/ bitstream/REPOSIP/275231/1/Marques_RenatoFranciscoRodrigues_M.pdf

MELO NETO, F. P. Marketing Esporitvo. Rio de Janeiro: Best Seller, 2013.

MOREIRA, D. Marketing Esportivo, Turismo e Museu: (In) conciliáveis? Séries Iberoamericanas de Museología. Madrid, v. 3, p. 109-121, jan 2012.

NEUHOFER, B.; BUHALIS, D.; LADKIN, A. Conceptualising technology enhanced destination experiences. Journal of Destination Marketing \& Management, v. 1, n. 1, p.36-46, nov 2012.

OLIVEIRA, A. P. Turismo e Desenvolvimento: planejamento e organização. 5a. ed. São Paulo: Atlas. 2005.

PAFFRATH, R. E.; CASSOL, V.J. Gaming abroad: o uso e gamificação no projeto de um sistema para apoio a turistas. XIII SBGames, p. 429-437, 2014.

PEZZI, E.; VIANNA, S. L. G. A Experiência Turística e o Turismo de Experiência: um estudo sobre as dimensões da experiência memorável. Turismo em Análise, Brasil, v. 26, n. 1, p. 165-187, mar. 2015.

PINE II, B. J.; GILMORE, J. H. The experience economy: work is theatre and every business a stage. Boston: Harvard Business School Press. 1999.

PORTA, E. El Tour del Bernabéu, el museo más rentable de Madrid. El Economista, janeiro, 2016 Disponível em: http://www.eleconomista.es/madrid/noticias/7271640/01/16/El-Tour-del-Bernabeuel-museo-mas-rentable-de-Madrid.html. Acesso em: 16 de juhlo de 2017.

REAL MADRID CLUB DE FÚTBOL. Tour Bernabéu. Disponível em:http://www.realmadrid.com/pt/bilhetes/ tour-bernabeu. Acesso em: 19 de julho de 2017.

RIBEIRO, N. A. I. O Turismo Desportivo como estratégia de competitividade para destinos turísticos: o caso da região de Lisboa. 106p. Dissertação (Mestrado em Gestão) - Instituto Superior de Gestão - ISG, Lisboa, 2014.Disponível em < https://comum.rcaap.pt/handle/10400.26/9425>

ROSS, K. Health tourism: an overview by HSMAI marketing review. 2011. Disponível em:http:// www.hospitality.org/news/4010521.html. Acesso em 21 de junho de 2017.

SCHMITT, B. Marketing experimental. São Paulo: Nobel. 2000.

SELLITZ, C.; WRIGHTSMAN, L, S.; COOK, S. W. Métodos de pesquisa das relações sociais. São Paulo: Herder. 1965.

SILVA, J. C.; MENDES FILHO, L. A. M. A influência das tecnologias da informação e comunicação nos destinos turísticos inteligentes. In: XXI Seminário de Pesquisa do CCSA: Cidadania em tempos de intolerância. Natal, RN. 2016.

SORIANO, F. A Bola não entra por acaso - Estratégias Inovadoras de gestão inspiradas no mundo do futebol. São Paulo: Princípio. 2010.

SOUZA, I.; ALVES, L. Jogando nos Museus Virtuais - Considerações preliminares: os jogos online como experiência educativa nos museus virtuais brasileiros. In SB GAMES. Salvador, BA. 2011

TRIVIÑOS, A. N. S. Introdução à pesquisa em ciências sociais: a pesquisa qualitativa em educação. São Paulo: Atlas. 1987.

VERGARA, S. Projetos e relatórios de pesquisa em administração. 3a. ed. Rio de Janeiro: Atlas. 2000.

ZIKMUND, W. G. Business research methods. 5a. ed. Fort Worth: Dryden. 2000. 
Marcio Ferreira Bezerra, et al. Turismo esportivo de experiência em museus e tours em estádios de ...

\section{Notas}

1 Os endereços eletrônicos visitados foram: https://turismo.buenosaires.gob.ar/es; https://www.esmadrid.com/pt; http://www.barcelonaturisme.com/wv3/es/page/96/museos-deportivos.html; http://www.visitlisboa.com.

2 No caso do Maracanã, as informações podem ser encontradas no endereço www.visit.rio.

\section{BY}

